\title{
Musulmanes de Padua: \\ sobre las nuevas identidades islámicas italianas
}

\author{
Padua's Muslim: on the new Italian Islamic identities
}

Agustina Adela Zaros *

\begin{abstract}
Resumen
El texto propuesto reflexiona sobre la comunidad musulmana en Padua y sobre las familias entrevista das en particular con el objetivo de individuar las prácticas de la transmisión de creencias al interior de la familia y de la continuidad del grupo creyente. Principalmente a partir del desarrollo de tres puntos centrales: la socialización religiosa, la representación de la comunidad como umma, según el mandato coránico de dar al islam y en la dicotomía nosotros/ellos de los discursos. Por último se abordan las significaciones de las identidades regidas por lo étnico y/o lo religioso y las nuevas generaciones con sus debates y luchas actuales identificadas como Nuevas identidades colectivas. Es decir, la reinterpretación permite el surgimiento de una nueva identidad colectiva que hace uso de prácticas que entran en tensión con la sociedad de acogida emergiendo como fuerza política.
\end{abstract}

Palabras claves: religión; transmisión; Islam; generaciones.

\begin{abstract}
The proposed text reflects on the Muslim community and families in Padua including interviews in order to individuate the practices of the transmission of beliefs within the family and the continuity of the group. Mainly from the development of three main points: religious socialization, community representation as umma, according to the mandate of Give to Islam as well of the dichotomy we Muslims / they Christians discourses. Finally, the meanings of identities governed by ethnicity and / or religion and new generations with current debates and struggles identified as new collective identities. That is, the reinterpretation allows the emergence of a new collective identity that makes use of practices that are in tension with the host society emerging like a political force.
\end{abstract}

Keywords: religion; transmission; Islam; generations.

Artigo recebido em 31 de dezembro de 2014 e aprovado em 22 de junho de 2015.

* Dra en Ciencias Sociales por la Universidad de Padova con una tesis en sociologia de la religion. Magister en Comunicacion y Cultura por la Universidad de Buenos Aires. Lic. en Comunicacion Social. Pais de origen: Argentina. E-mail: agostinazaros@gmail.com. 


\section{Introducción}

El siguiente texto está compuesto por reflexiones sobre la comunidad musulmana del norte de Italia a partir de una investigación empírica en Padua y entrevistas en profundidad a tres familias musulmanas con más de diez años de residencia en la ciudad ${ }^{1}$. El objetivo principal busca indagar sobre la transmisión religiosa y sus prácticas tanto al interior de la familia como en la comunidad de referencia.

La comunidad musulmana actual es heterogénea y diversa y, las familias elegidas para las entrevistas encierran un poco esa diversidad del campo. En la provincia de Padua los migrantes musulmanes provienen principalmente del Magreb y en su mayoría de Marruecos, que tiene una presencia muy fuerte a través de diversas asociaciones. El acceso al campo por parte del investigador se realizó a través de contactos personales más que de las instituciones presentes.

Ha habido dos grandes oleadas de inmigración en Italia proveniente de los países árabes, la primera en los años setenta, con la llegada de jóvenes de origen urbano alfabetizados e islámicos militantes, y la segunda en los años noventa, más irregular y caracterizada por la llegada de familias (BOMBARDIERI, 2011). María Bombardieri explica que esta última oleada es la que constituye el "pueblo" de las mezquitas, mientras que la primera dio lugar a la creación de las primeras organizaciones y las organizaciones musulmanas en los años ochenta y noventa (BOMBARDIERI, 2011, p. 23).

Según Rhazzali \& Equizi (2013, p. 54),

\footnotetext{
${ }^{1}$ Los nombres de los entrevistados son ficticios, la investigación fué aprobada por la Universidad de Padua (UNIPD) y se enmarca en la tesis de doctorado en Ciencias Sociales de dicha casa de estudios.
} 
la presencia islámica en Italia se fue construyendo en un periodo relativamente corto, sobre todo durante las últimas dos décadas. Por lo tanto, se trata de un Islam migrante, de primera generación, marcado por la situación actual cultural y política de los países de origen, donde en este momento se incrementa en gran medida la importancia del Islam en el espacio público.

Padua se caracteriza por ser una región industrial del noreste italiano y muchos migrantes se asentaron en busca de trabajo, además es una ciudad universitaria y fue el lugar de uno de los centros islámicos más antiguos del país. Es la segunda sección de la Unión de estudiantes musulmanes en Italia (USMI), que se remonta a principios de los años setenta.

Cómo los italianos cuando migran a otros países, los musulmanes italianos se han organizado en asociaciones como la Unión de Comunidades Islámicas en Italia (UCOII), las asociaciones juveniles como los Jóvenes Musulmanes de Italia y la reciente Asociación de Scouts Musulmanes, y desde 2012 la Asociación Islámica de Imanes y dirigentes religiosos, para tratar la formación de líderes en un contexto como el italiano. También es importante el papel desempeñado por muchos centros islámicos y mezquitas en el apoyo a las familias en las responsabilidades educativas para con sus hijos y en la promoción de los campings para la enseñanza del Corán y conferencias sobre el Islam.

Los musulmanes están presentes visiblemente en el espacio público a través de momentos de agregación y formas de asociaciones que inicialmente dan prioridad a la preservación cultural y su identidad religiosa para reclamar el derecho a mantener su propia diversidad cultural y religiosa en Italia. El asociacionismo de tipo religioso tiende a predominar sobre otros principios nacional, lingüísticos o ideológicos, secular. De todas maneras, las asociaciones se diferencian por la provenienza etno-nacional, pero mantienen su identificación con el islam en primer lugar (RHAZZALI; EQUIZI, 2013, p. 54).

El autor también destaca que los italianos convertidos al Islam han acompañado el crecimiento de la presencia islámica en Italia y el papel del Sufismo de inspiración italiana ha contribuido a las asociaciones y organizaciones. 
Principalmente, el sufismo representa una de las tradiciones más atractivas del islam para los convertidos italiano que privilegian la cultura filosófica y teológica con diversas actividades públicas de difusión y editoriales.

Según el reporte anual de Caritas/Migrantes de 2012 los musulmanes en Italia son 1.645.902, de los cuales 506.369 de Marruecos, 491.495 de Albania, 122.595 de Túnez, 117.145 de Egipto, 106.671 de Bangladesh, 87.311 de Senegal, 90.185 de Paquistán y 28.081 de Algeria.

La investigación de María Bombardieri relevó 137.000 musulmanes en la región del Veneto, alrededor de 5000 en Padua de los cuales 2035 de procedencia del Magreb y 1449 de Marruecos; una comunidad islámica organizada y presente desde 1986. Asimismo, identificó 21 lugares de oración incluyendo 2 habitaciones en Padua, 2 grupos sufís, 2 asociaciones muridi² y 2 senegalesas, 1 de la comunidad de Bangladesh (BOMBARDIERI, 2011, p. 72).

A Italia no escogió su propio modelo de integración cultural como el asimilacionista francés o multiculturalista de Inglés, y por lo tanto mantiene una política de exclusión, con acuerdos con diversas denominaciones (entre ellas el judaísmo), pero no con la comunidad musulmana. El italiano Renzo Guolo llama a esta realidad "asimilacionista sin asimilación", debido a que la asimilación ofrece como posibilidad la ciudadanía. El autor afirma que

el Islam es un problema para la sociedad italiana: las diferencias culturales y religiosas que conlleva la divide. Por lo tanto, el Islam interroga dramáticamente a la sociedad italiana en su propia identidad, en su cohesión, en su historia [...] el 'musulmán' aparece a los ojos de muchos italianos como antropológicamente 'otro' (GUOLO, 2003, p. V-VI).

Por esto, las organizaciones juveniles, como los Jóvenes Musulmanes de Italia (GMI, la sigla en italiano) tratan de construir relaciones de pertenencia hacia

\footnotetext{
${ }^{2} \mathrm{Si}$ bien los muridi son en su mayoría de origen senegalés, tienen una organización de confraternidad por lo que adoptan una forma comunitaria en la cual sus lugares de culto son privados, en general se trata de departamentos o casas frecuentadas sólo por muridis.
} 
el país donde nacieron y la cultura en la que crecieron, con la posibilidad de ejercer su derecho a expresar su identidad religiosa.

Las políticas restrictivas en materia de ciudadanía y la idea difundida por los medios de comunicación del Islam como terrorismo hace que quien no sea italiano y católico ocupe un lugar de alteridad en un país que presenta nuevos desafíos a nivel cultural y religioso pero a los cuales el Estado parece no responder con acciones.

\section{Memoria familiar religiosa}

La investigación parte de una propuesta teórica que combina la idea de la religión a la de la memoria, en el sentido de que cada generación puede a reinterpretar lo que ha heredado (en términos de capital-religioso simbólico) con una trayectoria de continuidad entre el pasado y el presente, a través de una relación entre la esfera simbólica y las prácticas.

Según Muxel (2002), la memoria familiar es el presente de un pasado, el guardián de los recuerdos de infancia y fiel servidor de los deseos, de los intereses y de los reclamos y demandas del hoy.

Por su parte, Marianne Hirsch (2008) llama generación postmemory a las nuevas generaciones cuyos padres han sufrido un trauma en el pasado. Se refiere a la capacidad de transmitir en los recuerdos familiares las experiencias pasadas, como por ejemplo el legado del trauma del Holocausto entre los judíos que ha sido revisada por una nueva generación a través de las historias orales de familia. La familia es el lugar privilegiado de esta transmisión intergeneracional de la memoria (y no intrageneracional) a través de estas experiencias incorporadas, que aparece inscripta en el cuerpo de las personas. Así, la autora sostiene que la condición de postmemory es una construcción, una estructura profundamente arraigada en la transmisión generacional a nivel familiar y comunitario. Este concepto también puede pensarse en relación a otras comunidades que vivieron experiencias 
traumáticas, como el genocidio armenio, las guerras mundiales, las migraciones forzadas por ejemplo la guerra en Somalia.

Ricoeur llama memoria trans-generacional, a la sucesión de las generaciones y la define como:

una experiencia poderosa, que ayuda a ampliar el círculo más cercano en la dirección de un pasado que, a pesar de pertenecer a los de nuestros antepasados vivos, pone en comunicación con las experiencias de una generación diferente a la nuestra (RICOEUR, 2004, p 565).

En los casos estudiados, las religiones históricas se comportan como la memoria, rememoran el pasado en el presente; la memoria habitada puede definirse como las practicas de la vida cotidiana en sentido religioso, la religión vivida. La permanencia inscribe las formas de hacer, para comunicarse, para poner en práctica en la familia, la memoria se completa en la repetición, la reinterpretación en la transmisión a través de la apropiación de lo que se hereda y la construcción de significación. El recuerdo de la casa y del estar con la familia está inscrito en los recuerdos de la infancia y ligados a una vida religiosa como manifiestan las entrevistas.

La memoria se cristaliza en los lugares, dice Ricoeur, así como la memoria familiar lo hace en la casa. La memoria está compuesta por discursos religiosos, símbolos y prácticas a través de los cuales se transmite la religión y la religiosidad se reinterpreta generacionalmente.

La memoria habitada es esta experiencia particular de tiempo, que en el mismo tiempo en que se vive, conecta con el pasado compartido con otras personas que pertenecen a la misma comunidad. Pueden ser conocidos, familiares, o personas imaginarias. En el habitar reside la experiencia del tiempo, que es pasado y el presente al mismo tiempo, ya que "recuerda" pero no pertenece al presente sino al pasado, pero puede ser habitado sólo en el presente. Llamo "memoria 
habitada" a esta experiencia particular de tiempo en la cual, en el momento en que es vivido conecta a un pasado compartido con la comunidad de pertenencia.

Este "habitar" la memoria se relaciona con el hogar en donde se pone en cuestión la dimensión familiar y la contemporaneidad del pasado y el presente de los rituales cuando se ponen en práctica. Las formas de habitar la memoria serán tratadas mas adelante en relación a la identidad musulmana y como reinterpretación de las nuevas generaciones sobre la religión.

A continuación el texto está organizado a partir del desarrollo de tres puntos centrales para analizar en relación a las familias musulmanas entrevistadas: la socialización religiosa, la representación de la comunidad como umma, según el mandato coránico de dar al islam y en la dicotomía nosotros/ellos de los discursos. Por último, se abordan la significación de las identidades regidas por lo étnico y/o lo religioso y las nuevas generaciones con sus debates y luchas actuales.

\section{Islam italiano}

En las situaciones estudiadas, un joven musulmán debe renovar y mantener su fe y sus prácticas en un contexto de mayoría católica que manifiesta hostilidad hacia la diversidad religiosa. El individuo que pertenece a una minoría religiosa tiene que lidiar con esta decisión y la escuela emerge como un espacio que destaca la diversidad y la minoría.

Cada generación crea sus propias tradiciones, que se toman desde el pasado y se reinterpretan, como por ejemplo, en la observancia de las leyes alimentarias. Entre las jóvenes entrevistadas aparece una interpretación del uso del velo según la experiencia de vivir en Italia al igual que el concepto de ser 'púdica' en relación a la vestimenta. Es decir, se articulan conceptos relacionados con lo femenino en el islam desde interpretaciones occidentales y en particular de referencias italianas para juzgar las prácticas religiosas de la mujer musulmana en Italia. 
El control social de la comunidad musulmana es ejercitado por los propios musulmanes, que tienen el poder de juzgar la conducta "socialmente visible" de los miembros de la comunidad, desde el discurso de la legalidad o ilegalidad, sino también en contraste Italiano-católico / musulmán en relación a qué está permitido y qué no.

El sentido de alteridad en el contexto italiano está relacionado con la hostilidad de los italianos en referencia a los migrantes musulmanes. La sociedad italiana está representada por los entrevistados como cristiana y al mismo tiempo como un lugar inseguro y de tentaciones para la vida en la religión musulmana.

En el caso de las nuevas generaciones musulmanas, esta tensión puede reinterpretarse como una forma de provocación por parte de los jóvenes musulmanes que reivindican las características del islam en Italia como posibilidad de existencia.

En relación con esto, la controversia generada por los crucifijos y el uso del velo no son generadas por las prácticas precisas, sino por que estos símbolos representan grupos de dispositivos islámicos como en la imaginación de la población.

De esta manera, los musulmanes resaltan la identidad religiosa fragmentada de los italianos y de una tradición católica que sólo existe en el imaginario pero no se vislumbra en prácticas religiosas sino que se traduce en una pertenencia de apariencia.

El Islam vivido en Italia lleva a cabo diferentes manifestaciones: por un lado, el Islam es la manera de crear una experiencia común entre los musulmanes que viven en Italia. Otra interpretación puede pensarse como "en devenir", es decir constituida por una interpretación italiana (de los musulmanes y convertidos italianos) en tensión con el Islam de los países árabes. Por último, um enfoque del 
Islam en lucha constante con la visión que lo define como terrorrismo, en gran parte construida por la imagen fomentada por los medios de comunicación después de Septiembre de 2001.

Sentirse perteneciente acá o allá al mismo tiempo es un sentimiento que experimentan algunos de los encuestados que se siente como Khalid y Amina que nacieron en Marruecos pero afirman sentirse mejor con amistades de su misma edad italianos.

La construcción de la identidad no tiene que ver con el territorio, pero con las maneras de apropiarse y combinar las prácticas que vinculen la pertenencia a las comunidades imaginadas. Asimismo, las dinámicas del tránsito y la comunicación son cada vez más transnacionales.

Entre los musulmanes la autoridad no proviene de las instituciones históricas y en la comunidad se pueden encontrar las asociaciones que gestionan los lugares de oración y, en algunas ciudades, mezquitas, y diversas formas de agrupaciones formadas por musulmanes que emigraron de los países árabes y convertidos de origen italiano.

La comunidad musulmana parece ser muy heterogénea, en particular, en Padua también está la influencia de países como Marruecos (el país con mayor presencia migratoria en el norte de Italia) con sus presencias institucionales y políticas que financian servicios como los lugares de culto, publicaciones, cursos en árabe, escuelas Corán.

La falta de otras estructuras de socialización religiosa, como las escuelas coránicas y de las mezquitas no coinciden con las expectativas de los jóvenes musulmanes europeos, que buscan otros contextos de fraternidad electiva (HERVIEU-LÉGER, 1993, p. 139) o que participan en más de un grupo al que sienten pertenencia. 
Según Sant Blancat (2004), hay una reestructuración de la transmisión religiosa con la subjetividad de la fe, en la que la familia no es suficiente para controlar el comportamiento de los individuos. Según la socióloga, el pluralismo es la opción estratégica de liderazgo en el espacio público y la apropiación del espacio como tácticas de supervivencia, tales como el desarrollo de las prácticas sociales y políticas flexibles que sirven a negociación en diferentes situaciones. Rhazzali \& Equizi (2013, p 6o.) señala que excepto para en el caso de la mezquita de Roma, institucionalmente reconocida como una organización sin fines de lucro, todos los otros lugares de culto de Italia no están reconocidos desde el punto de vista jurídico, la naturaleza de lo que constituye una connotación religiosa en sí misma no es jurídicamente relevante. Del mismo modo, como señala el autor, el Islam no es legalmente un "culto permitido en la ausencia de un acuerdo con el Estado."

Para satisfacer las necesidades de las experiencias locales han surgido organizaciones locales, tales como el Consejo Islámico de Verona ", que se caracteriza por su origen homogéneo de los miembros [...] que cruza el tema de la identidad nacional con la pertenencia a la religión islámica” (RHAZZALI; EQUIZI, 2013, p. 65).

En este contexto que acabamos de describir, los siguientes extractos revelan la necesidad que surge de las entrevistas vinculadas a la necesidad de apoyo de las escuelas coránicas en la socialización religiosa.

\section{Sobre la socialización religiosa}

En este apartado, se hace referencia a las diferentes prácticas de la socialización religiosa tanto al interior de la familia como en la comunidad de Padua en relación a la continuidad del linaje creyente y a transmisión de creencias a los descendientes. 
En Padua hay dos mezquitas, donde se asiste sobretodo el viernes para la oración, además se realizan actividades para niños y funciona una guardería, también se realizan reuniones temáticas, conferencias con teóricos invitados a hablar sobre diferentes aspectos del Islam y es el lugar donde ser reúnen los Scouts musulmanes de Italia.

Las primeras observaciones de campo se llevaron a cabo al asistir a la reunión anual de los jóvenes musulmanes de Italia, en la víspera de Año Nuevo de 2011. La reunión incluyó tres días de debate en un complejo de verano junto al mar en un gélido diciembre. Allí conocí en especial a mujeres de diferentes edades, adolescentes e incluso las madres y abuelas que acompañaron a sus hijos porque compartía con ellas la habitación y las comidas.

Recurrí a éstas jóvenes y mujeres que había conocido en ese campamento de invierno y a través de sus contactos logré identificar familias que viven en Italia desde hace más de diez años que aceptaron ser entrevistadas.

Durante las entrevistas estas familias se mostraban amables y cariñosas, y en muchos casos compartía el té con ellos. Muchas veces me identificaban como italiana (y por esto "cristiana"), hasta que les explicaba y pasaba a ser argentina y por lo tanto "extranjera". Ya que en relación con la alteridad, como se tratara más adelante, los entrevistados muchas veces responden desde la comparación entre los musulmanes y los italianos (cristianos).

Los fragmentos de entrevista que se reproducen a continuación hacen referencia al rol de las escuelas coránicas como instituciones que vienen a colaborar en la socialización de los hijos además de la familia de origen.

Abdel (61 años): tenemos una escuela coránica [...] hay una casa, uno que vive que sabe leer el Corán, todo el mundo llevan a sus hijos a aprender el Corán ahí.

Khalid (34 años): una pequeña escuela para la religión musulmana aquí en Padua, todas las familias que llevan, incluso las mujeres que no saben leer, hay veinticinco mujeres, de treinta años que no saben leer, entonces hacen un curso gratuito dos veces por semana... 
Como destacan los relatos, una persona de la comunidad pone a disposición su experiencia al servicio de la comunidad, ya que, según la historia de Abdel, si no se llega a Italia con el conocimiento de la religión es más difícil después enseñar a los hijos. Del mismo modo, Khalid resalta la necesidad de las mujeres de prepararse para enseñar a sus hijos, sobre todo en un contexto diferente al de los países árabes.

Julia nació en Italia, su socialización religiosa en el Islam es italiana, sólo conoce Marruecos por las vacaciones o las bodas, no sabe leer árabe, y dice que sus hermanos le traducen las enseñanzas del Corán en italiano.

Giulia (20 años): fui a clases [...] Recuerdo que mi hermano me llevaba los domingos a la tarde, me enseñó las letras árabe, aprendí cosas nuevas, incluso palabras porque nosotros hablamos dialecto marroquí, después dejé porque no quiero aprender árabe, tenía dieciséis años, hice unos meses. (Mi hermana) fue desde los seis años, ahora tienen ocho [...] la bocharon dos veces, es muy difícil.

Abdel (61 años): desde pequeños comienzan a aprender el Corán, tres años, poco a poco, después de los cinco años tiene el cerebro (para entender) [...] Entonces los niños estudian casi un año, un año y medio, dos años, dependiendo de si es despierto, aprenden a leer en un año.

Rania (22 años): a partir de los trece... empecé con cursos de árabe, a estudiar el Corán y luego una cuestiones de religión...

Abdel señala que la socialización religiosa comienza cuando el niño está en condiciones de comprender el idioma árabe del libro sagrado. Por otra parte, Rania llego a Italia a la edad de siete años, cuando comienza la socialización religiosa en Marruecos con las escuelas coránicas; a diferencia de la familia de Khalid donde todos los hermanos la han frecuentado de niños.

Rania nació en una familia observante, lleva un pañuelo en la cabeza, a diferencia de la madre de Khalid, y es una chica que participan en organizaciones juveniles y de estudio de su religión, tal vez impulsado por este ideal de "Islam italiano" y "nuevos ciudadanos", em relación a la Italia emergente, como país de la 
diversidad. La experiencia de migración y religiosa en un país tradicionalmente católico parece motivar a estos jóvenes, como en el caso de Rania, a interesarse en el estudio de la religión y participar en propuestas políticas.

Sobre la evolución del papel de las instituciones, se ha vuelto cada vez más importante y difícil tener una red de mezquitas locales para la socialización de los niños y aprender el Corán, sobretodo en el norte de Italia por su orientación política de derecha.

La presencia de Padua en una escuela de Corán permite a los padres compartir la tarea de socialización religiosa de los niños en un país predominantemente católico, y es un espacio principalmente de socialización, para el debate y la formación comunitaria.

En los próximos fragmentos, Jamil recuerda como la comunidad musulmana fue construyendo un lugar para rezar en la zona en la que vive; dinámica que se ha repetido en la formación de otras salas de oración en los alrededores de Padua.

Jamil (29 años) era un garaje que una persona había cedido, en el sentido, ya que no teníamos un lugar donde nosotros los musulmanes rezar [...] casi un bunker, pero en fin [...] también hubo dificultades con los vecinos se quejan cuando escuchan la oración por la noche, esto paso hasta hace cinco años [...] más tarde, con mucho esfuerzo fue comprado otro lugar más amplio.

Rania (22 años): la mezquita también ayuda en mi opinión, además de los padres. No es la mezquita, no en el sentido de que vas allí a rezar, sino para ir a hacer los cursos, clases sobre religión [...] reuniones, que en mi opinión ayuda mucho, es también un lugar para el debate.

En Jamil la necesidad de un lugar para orar también está vinculada a la necesidad del reconocimiento de 'nosotros los musulmanes' también como habitantes del lugar con sus propias prácticas religiosas. En su relato el entrevistado se refiere al camino a través del cual las personas se han organizado para tener un lugar de oración, y la alteridad percibida por los vecinos para con los musulmanes. 
La mezquita no se ve como un espacio sagrado dedicado a la oración y diferente del espacio profano de la vida cotidiana, sino que ofrece cursos de árabe y guardería después de la escuela para los niños, es el modo de construir la comunidad al igual que las conferencias anuales que promueven la creación de redes entre grupos activos en varias ciudades de la región Veneto como Verona y Vicenza.

El mes del Ramadán es el período que los entrevistados recuerdan de la infancia en referencia a los rituales que congregan a la comunidad local como la fiesta más grande de los musulmanes en la cual durante un mes por año tienen en común la práctica del ayuno.

Jamil (hijo, M, 29 años): Me acuerdo del período de Ramadán, el clima festivo y juntarse a la noche para comer, y también me acuerdo de la televisión que media hora antes de empezar a comer leen el Corán, siempre recuerdo que se hacía muy largo el tiempo antes de empezar a comer.

Khalid (hijo, M, 34 años): La fiesta del cordero (cordero), cuando Abraham quiere matar a su hijo Ismael [...] Un buen (el hijo), entonces cuando el padre quiere matarlo entonces Dios le trae un cordero, un gran cordero, vamos a hacer esto que ha venido a decir la religión de la fiesta del cordero [...] comprar el gran carnero (cordero), aquí en Italia se prohíbe hacer estas cosas.

Jamil recuerda la atmósfera durante la puesta del sol y la comida compartida al finalizar el día, Khalid relata la fiesta religiosa del sacrificio, que es la segunda fiesta más importante del Islam y conmemora a Abraham; durante la entrevista me muestra la imagen de un cordero vivo dentro de la casa en la que estamos haciendo la entrevista haciéndome entender que sacrificaron el cordero en esa casa lo que es una usanza prohibida en Italia. La fiesta celebra a través del ritual junto a la comunidad y a la familia; dicha conmemoración en los hogares se celebra el "sacrificio" de un cordero que será compartido con todos (vecinos, parientes, etc). 
Entre las observaciones de campo realizadas una fue justamente la fiesta antes descripta, que es una de las festividades más importantes del Islam (la otra es la del fin del Ramadán). La celebración se realizó en un gimnasio alquilado para la ocasión, como sucede cuando hay días de fiesta multitudinarios con alta participación de la comunidad.

En la ocasión observada participaron alrededor de 300 hombres, 60 mujeres y 40 niños y adolescentes y el ingreso era diferenciado para hombres y mujeres. Los hombres estaban sentados en el frente, las mujeres y los niños detrás.

"Con este día finaliza el mes de Du al-Hiyya, que es el mes donde se hace la peregrinación a La Meca. El día anterior, se pide perdón por los pecados cometidos en el año anterior y se ayuna", explica una asistente.

La fiesta comenzó a las ocho y media de la mañana y había hombres que recitaban las canciones que parecían canciones repetitivas, seguidas de discursos en diferentes idiomas (dialecto marroquí, urdu e italiano) y luego la oración colectiva.

En relación con compartir la comida y tener en cuenta a los vecinos como parientes, Amina se refiere a esta dimensión colectiva, tal vez de origen religioso y también étnico, de compartir la cena.

Amina (hija, M, 27 años): es triste a veces tener que comer sólo nosotros cinco, sólo la familia, en cambio sábado y domingo es festivo y se siente este vinculo no solo por el hecho de ayunar sino por el sentimiento de unión.

Amina, sin embargo, habla de la importancia de compartir la primera comida del día después de la puesta del sol durante el Ramadán; compartir para ella lo hace más significativo y resalta la dimensión social de la religión y también la memoria colectiva que se actualiza en el ritual. 
A continuación, propongo dos extractos surgidos de las entrevistas y relacionados con el sentimiento de pertenencia al grupo: la primera es en relación con el comportamiento cotidiano como musulmán, sobre la ortopraxis.

Jamil (hijo, M, 29 años): Tengo que dar un buen ejemplo como musulmán, si digo que creo en Dios y creo que es mi salvación voy a tratar, si amo a los que me rodean, voy a tratar de imitar el ejemplo, comportándome como se supone debe ser. Esto fue el tema del salmo del viernes. Algunos amigos del profeta decían como se debe actuar, que no hay que robar, en cambio otros seguían su ejemplo, veían como vivía el Profeta y trataban de imitarlo.

El buen musulmán imita la vida del Profeta y frecuenta la mezquita; esta observancia implica la pertenencia a una confesión y la decisión (y la responsabilidad) de que la religión es el universo de sentido que guía la vida de la persona entrevistada, sus acciones y juicios.

Por último, sobre la participación y la pertenencia en la comunidad musulmana surge el tema de la militancia relacionada con la forma de participación y de representar la alteridad frente a la mayoría católica de la población italiana.

El sentido de comunidad ya no está unido a un territorio específico; la comunidad imaginada entonces crea una dimensión virtual, que reúne a aquellos que forman parte pero no se conocen y cuyo grupo se define sólo sobre la base de criterios islámicos. "Este espacio imaginario es el de una comunidad religiosa en un mundo hostil o indiferente" (ROY, 2003, p 120) y pertenece a una nueva generación que no incluye a sus padres.

Para continuar con la discusión de los musulmanes en Italia, en las asociaciones tienen la opción de construir un Islam decididamente italiano donde le sean reconocidos los derechos relativos a la libertad religiosa a través del instrumento jurídico de un acuerdo formal (RHAZZALI; EQUIZI, 2013, p. 54). 
Como ya señalaba Pace (1999, p. 214) en relación con las comunidades islámicas y el Estado, pedidos como la hora de religión islámica en las escuelas públicas, alimentos diferenciados que incluyan los permitidos para los musulmanes en los comedores de hospitales, prisiones, oficinas y escuelas; son prácticas que simbolizan el reconocimiento por parte del Estado italiano de la presencia de musulmanes italianos, cuya falta separa cada vez más el "nosotros" de "ellos".

Sobre los modos de habitar la memoria descriptos anteriormente uno es como "factor identitario", que es lo que los entrevistados llaman "el islam italiano" que constituye la experiencia de ser musulmán en Italia y la necesidad de reconocimiento de un Islam italiano para construir un islam europeo.

El concepto de un Islam italiano introduce una nueva perspectiva representada por la generación más joven, que se encuentran con la tensión de la sociedad italiana y con las concepciones de sus padres caracterizadas por el apego al territorio de origen.

Los niños nacidos y criados encuentran el país origen de sus padres (Marruecos y Somalia entre los entrevistados) en la comida, el idioma y la religión. De esta manera, el Islam no es el Islam sólo de los países arabes sino que también es posible pensar la construcción de un islam italiano y europeo como afirman los grupos de jóvenes musulmanes de Italia.

Este modo de habitar la memoria como "factor identitario" permite a los jóvenes musulmanes pensar como musulmán y como italiano. Dicha reinterpretación incluye varias referencias éticas, comunitarias y nacionales que conviven más allá de la religiosa. Estas perspectivas diferentes coexisten y entran en tensión en las diferentes maneras de representarse a si mismos.

Por último, otro modo de "habitar la memoria" en el caso de las familias musulmanas estudiadas es denominado "nuevas identidades colectivas", es decir por un lado está la familia de origen y la identidad religiosa que se transmite, pero se agrega la identidade nacional, en este caso italiana. Así pues, estas nuevas 
identidades colectivas definen la experiencia de ser musulmán en Italia como una forma de territorializar, es decir, de adaptarse a un nuevo entorno social tomando referencias culturales italianas.

En el caso de habitar la memoria como "nuevas identidades colectivas" la reinterpretación permite el surgimiento de una nueva identidad colectiva en cambio, en el caso de "factor identitario" se hace uso de prácticas que entran en tensión con la sociedad de acogida sin emerger como fuerza política, quedándose en la alteridad. Las nuevas identidades colectivas son la referencia del discurso de la generación más joven que reivindican luchas que se remontan a cuando sus padres emigraron a Italia, que siguen siendo necesidades no resueltas, con un discurso que viene de los grupos ya constituidos o como una provocación por ejemplo la que puede leerse en la literatura de Ghazy (2007) y Abdel Qader (2008) que son jóvenes mujeres musulmanas que cuentan sus experiencias cotidianas de vivir en Italia como musulmana.

A continuación se desarrollara la dimensión comunitaria del grupo y como se ha construido la representación de ellos mismos en relación a los recorridos migratorios y a la relación con el país de acogida que contextualiza las tensiones antes descriptas.

\section{Construcción de una comunidad}

De las entrevistas con las familias y el trabajo etnográfico durante las fiestas religiosas y conferencias, la comunidad emerge como una categoría del discurso en la contraposición entre el "nosotros musulmanes/ustedes italianos" que por momentos incluye a la investigadora que es identificada en un cruce entre católica/extranjera y occidental. 
Esta referencia al 'nosotros musulmanes' es la manera de construir un sentido de pertenencia con la comunidad relacionada con el concepto de dar al Islam3 (PACE, 1999), que en esta interpretación es una forma de representarse a sí mismos como musulmanes y reclamar el derecho de expresar su religión. La casa, en lugar de la comunidad, es representada con un concepto que viene de la doctrina legal y religiosa de la Edad Media "habitar la casa del Islam”, a diferencia de otras casas, por ejemplo la de los "cristianos".

"Dar" entendido como sentido cultural y político, es un reflejo mental de clasificarse según la dicotomia "nosotros/ellos" sumado al desarrollo del sentido de la diversidad (xenófoba) a partir de lo vivido desde 2001 en Italia.

En la comunidad estudiada, el Islam deconstruye la etnia en el sentido que la identidad musulmana y la experiencia migratoria agrupa a la comunidad independientemente de la diferencia étnica y como consecuencia de la alteridad para con la población local. En los próximos pasajes de entrevistas se exponen la temática del discurso de "nosotros" (musulmanes) en contraposición a "ellos" (italianos).

Khalid (hijo, M, 34 años): entonces, si sos musulmán, si sos cristiano, entonces vos poder hacerme un favor, me dejas rezar cinco minutos y trabajas en mi lugar, algunos no tienen problema, pero hay otras personas no lo hacen.

Nasim (TP, M, 27 años): Podemos encontrar una chica tan buena [...], porque ha recibido una educación musulmana, su padre fue a la mezquita y así alhamdulillah, (gracias a Dios) Mientras que podemos tener una”. otra chica que va los sábados, ¿dónde está? busca un club nocturno, tal vez le dice a su padre, que va a estudiar, tal vez pasa la noche, hay tantas historias, incluso de los padres que he conocido esta ciudad [...] muchos se alegran cuando saben que el hijo tiene una novia italiana.

Khalid se refiere a la empresa donde trabaja su hermano en donde no le dan el tiempo para hacer sus oraciones durante el Ramadán. Nasim, por su parte, distingue entre una joven educada religiosamente y los jóvenes musulmanes que tienen hábitos italianos y padres permisivos.

\footnotetext{
${ }^{3}$ Además de casa u hogar también puede interpretarse como tierra del islam o territorio.
} 
A continuación en los siguientes extractos Rania, explica cómo algunas practicas como pedir perdón y la oración, estableciendo una comparación con el catolicismo. Amed se refiere a los jóvenes musulmanes que conoce y el peligro de la pérdida de la observancia en el contexto de la sociedad italiana.

Rania (TP, M, 22 años): si hemos cometido un pecado, le pedimos perdón a Dios, directamente... a diferencia de los cristianos que tienen... (Confesor) que actúa como intermediario.

Amed (hijo, M, 26 años): acá en Italia muchos jóvenes no hacen las oraciones, ni siguen el Ramadán [...] existe el problema de las escuelas donde hay crucifijos, los chicos escuchar música, escuchan historias, cuando el niño estudia con chicas cristianas te digo, a muchos no les importa que son musulmanes [...] es como una computadora, cuando instalas algo nuevo (aplaude) y listo.

En el último extracto de Amed señala que, como un nuevo sistema operativo que borra lo preexistente, los jóvenes empiezan a comportarse como la sociedad de acogida perdiendo las prácticas consideradas como pilares en la religión islámica.

En el caso de los migrantes transnacionales, escribe Gandolfi (2006, p. 56), haciendo referencia a su investigación "esta conciencia de pertenecer a un grupo específico, distinto del país de origen y de la sociedad de acogida, aparece claro en la dicotomía 'nosotros/ellos", que emerge de las entrevistas, así como la idea de un papel desarrollado en diferentes contextos y espacios de forma simultánea.

En relación con la comunidad se puede encontrar en el Corán: "Señor, haznos sumisos a ti, haz de nuestra descendencia una comunidad sumisa a Ti, y muéstranos tus ritos, tú que eres el Indulgente, el Misericordioso (IL CORANO, 2: 128)".

En mi investigación, los entrevistados musulmanes no hablan de la comunidad en estos términos, ni con el concepto árabe de umma. Este «nosotros musulmanes» se define en oposición a la mayoría de la población italiana y católica 
y dentro de los mismos parámetros con los que sienten que el no musulmán italiano los define como inmigrantes musulmanes.

Según Allam (2003), en los países musulmanes, el Estado es quien organiza la comunidad como hace la Iglesia para los católicos, pero el Islam en el extranjero no se organiza en términos de pertenencia territorial. Sobre esto Roy (2003) argumenta que la distancia que la migración y la minoría religiosa crea entre el creyente, por un lado y el poder político, o el resto de la sociedad, por el otro, lleva a reformular el concepto de comunidad, a encontrar un nuevo significado al hecho de definirse creyente. En este contexto, el Islam tiene como objetivo superar la identidad étnica de origen para establecer una identidad común estrictamente religiosa influyente y universal, pero se transforma en el símbolo de una nueva etnicidad, en la que el musulmán es sólo ocasionalmente creyente y practicante (ROY, 2003, p. 57).

Dichos desafíos quedan planteados en las bases de la comunidad musulmana europea cuya tensión deja en evidencia el cambio generacional entre los migrantes y los musulmanes nacidos en Italia.

\section{Un Islam migrante}

Dice El Corán: "se forme de ustedes una comunidad de hombres que atraen el bien, ordenan la justicia y evitan la injusticia, he aquí los afortunados" (IL CORANO 3: 104).

La comunidad musulmana aparece dispersa y difícil de estructurar. Por ejemplo, entre los somalíes la organización de la comunicación está basada en lo étnico-nacional y en relación con otras comunidades somalíes en diáspora; en el caso de la familia entrevistada, los padres son miembros activos de la comunidad, y los hijos e hijas se casaron con somalíes que viven en Canadá y Suiza. 
Otro aspecto de la migración a occidente es la desconexión del Islam como una religión de una cultura particular, que conduce a los actores a tener que reformular individualmente una religión que ya no está respaldada por la sociedad (ROY, 2003, p. 15), es decir un Islam por fuera de los países árabes donde es necesario definir nuevas categorías y diferentes a las del país donde nacieron ellos o sus padres.

Este autor hace referencia a la reformulación del Islam y a su desapego de la cultura de origen, que se basa en el trabajo de la religiosidad y la forma en que el creyente vive la experiencia religiosa en el país en el que se migra. Roy señala dos aspectos de este fenómeno: el neo-fundamentalismo, como un intento de definir una nueva comunidad sobre la base de un estricto código de conducta (que es esencial en la dimensión legal), y su opuesto, la reformulación de la religiosidad en términos de la fe, el logro individual y los valores (ROY, 2003. p 50).

Por su parte, Saint-Blancat (2004) explica cómo las primeras familias musulmanas asentadas en Europa en los años 6o, afrontaron un doble proceso de condiciones socio-económicas precarias, por una parte, y la falta de estructuras comunitarias de tipo religioso. De esta manera, sus hijos han sido socializados en un contexto de fuertes cambios en relación a lo religioso, de búsqueda individual y preguntas acerca de la autoridad.

En los casos estudiados, la primera familia marroquí llegó hace diez años, la madre y uno de los cuatro hijos, en la actualidad viven en Italia dos de sus hijos, una nuera, un nieto y su marido. La segunda familia marroquí llego hace más de veinte años, primero el padre y luego la esposa y dos hijos, las dos hijas menores nacieron en Italia. Finalmente, la familia somalí llegó a Italia después de pasar un año en Yemen. La madre de Nadia había estudiado en Italia y de esa manera tuvo la oportunidad de aprender sobre el idioma y conocía el país. 
Latifa (madre, M, 57 años): Diez años [...] vine aquí por primera vez en 2002, y él (el esposo) tenía que venir (cada) tres meses de visita.

Nadia (hija, M, 26 años): nos fuimos por la guerra en Somalia, no se podía venir directamente a Italia [...] ningún avión llegaba a Italia desde allí, entonces nos tuvimos que ir a Yemen [...] donde estuvimos un año.

En el primer caso, Latifa hace referencia a los permisos legales para poder permanecer en Italia, mientras que la familia de Nadia tuvo un recorrido diaspórico hasta llegar a Padua. Por su parte, Nassim describe en el siguiente extracto el perfil de las familias migrantes en esta región provenientes de Marruecos (un gran porcentaje de los migrantes musulmanes en Véneto provienen de Marruecos como se mencionó anteriormente).

Nasim (TP, M, 27 años): no son personas que tienen un título, las que migraron para mejorar el aspecto económico, la mayoría no son practicantes [...] Después surgió el problema, ahora piensan en orar, en hacer mezquitas, le piden a Italia que acepte el Islam como religión.

Nasim refiere a la necesidad de crear referencias institucionales que den cuenta de la presencia islámica en Italia, que permite la continuidad de la socialización religiosa en un contexto diferente a los países árabes y la mayoría católica. Esto no era un "problema" para los migrantes, pero ahora es una necesidad porque Italia ya no es un lugar de tránsito sino un país de residencia y necesita un apoyo institucional para la socialización religiosa de la comunidad más allá de la familia.

En una de las familias entrevistadas aparece la idea de regresar a Marruecos aunque hace diez años que viven en Italia, ya que no creen que se pueda educar a un nieto en Italia. Por esta razón, para las familias se volvió importante desarrollar instituciones que colaboren en la socialización religiosa de sus hijos para apoyar la formación recibida en la casa, como fue tratado anteriormente.

Según Saint-Blancat (2006), el desafío que enfrentan los jóvenes musulmanes es justamente construir una sociabilidad religiosa más transnacional y europea que comunitaria. Estos empiezan a reestructurar sus relaciones de acuerdo 
a una línea de creencia, pero necesitan construir espacios institucionales para la transmisión de estas creencias que garanticen la legitimidad de su continuidad en contextos de diversidad religiosa.

A continuación se proponen reflexiones finales que retoman los temas expuestos en estas páginas y a los debates actuales que dejan en evidencia las tensiones presentes entre la comunidad musulmana en Padua y las que surgieron de las familias entrevistadas para esta investigación.

\section{Ultimas reflexiones}

La migración permite la formación de redes entre comunidades en diáspora en diferentes países. Estas experiencias comportan también una experiencia particular de la alteridad relacionado al lugar del migrante y la representación de la sociedad hospitante.

Para los musulmanes, la tensión se experimenta en la práctica de la religión en un país donde todo a su alrededor no es musulmán y en el contacto con el Otro, emerge la "visibilidad" de la minoría.

Sin embargo, es la alteridad que se vive como una lucha con la cultura del país de acogida. La sociedad italiana es vista como una amenaza a su cultura donde el niño fuera de la casa de la familia comparte con las personas que se comportan de una manera diferente y sus amigos son italianos. Khalid señaló también que el niño puede regresar a Italia cuando recibió la formación religiosa en un país árabe, volviendo el concepto de religión unida a la nación, sin un concepto de Islam a nivel italiano o europeo. De esta manera, según los entrevistados solamente con una mentalidad islámica, firme y árabe un joven podría vivir en un país como Italia, con menos riesgo de ser influenciado por el comportamiento de los italianos. 
En un país culturalmente católico no hay necesidad de hacer visible la catolicidad, porque está presente en el contexto; em cambio una religión diferente es susceptible de ser absorbida por el contexto y desaparecer. Es importante tener en cuenta que el norte de Italia del Norte es un ambiente hostil para los inmigrantes y para el Islam en particular, y tiene una imagen negativa alimentada por los medios de comunicación y los partidos políticos, de extrema derecha como la xenófoba Lega Nord (GUOLO, 2003).

En la alteridad se trata de fortalecer la identidad religiosa no tanto para resaltarla sino para ser más fuerte ante la mirada del Otro católico y es ahí donde emerge de manera clara la comunidad frente al peligro de desaparecer y las diferencias nacionales de las distintas proveniencias de África pierden peso.

La tierra de origen, para las familias marroquíes se mantiene como el sitio de un eventual retorno (imaginario) para padres e hijos aunque vivan en Italia desde hace más de 10 años. Los hijos, en cambio tienen una relación diferente con el país de origen de sus padres ya que nacieron o se criaron desde la infancia en Italia y regresan a Marruecos para las vacaciones y para casarse. Tienen una relación hostil con el país anfitrión por la condición de migrante y recuerdan lo difícil de la adaptación durante los primeros años en Italia.

Los somalíes entrevistados tienen una relación con la comunidad imaginaria que constituye la comunidad somalí en el mundo y no existe un concepto de mito de retorno al país de origen en la familia entrevistada ya que también es una imposibilidad concreta por la guerra en ese país. Los matrimonios de los hijos de esta familia están casados con personas de las comunidades somalí de otros países. La sensación de pertenencia en relación a dos países diferentes al mismo tiempo también emerge en los jóvenes entrevistados, como Khalid o Amina que nacieron en Marruecos pero afirman sentirse mejor con los chicos y chicas de su misma edad italianos. 
Por último, el concepto de la confesión se asocia con el origen étnico y así los musulmanes pertenecen a los países árabes. El concepto de un Islam italiano introduce una nueva perspectiva que está representada por una generación más joven, donde los problemas de la sociedad italiana se resignifican a diferencia de la generación de sus padres que se caracteriza por el apego al territorio de origen. Los niños nacidos en Italia viven en el país donde nacieron y se criaron y el país de origen de sus padres (como Marruecos o Somalia) está presente en la cotidianeidad a través de la comida, el idioma y la religión.

\section{REFERENCIAS}

ADDEL QADER, S. Porto il velo, adoro i Queen. Milano: Songogno Editore, 2008.

ALLAM, K. L'islam globale. Milano: Rizzoli, 2003.

ALLIEVI, S. Islam italiano: Viaggio nella seconda religione del paese. Torino:Einaudi, 2003.

BOMBARDIERI, M. Moschee d'Italia: il diritto al luogo di culto: il dibattito sociale e politico. Bologna: EMI, 2011.

CARITAS. Fondazione Migrantes e Caritas Diocesana di Roma. Dossier statistico inmigrazione. $22^{\circ}$ Rapporto Caritas/Migrantes, 2012

GANDOLFI, P. Lo spazio transazionale e i migranti marocchini: essere coinvolti nei processi di sviluppo sfruttando l'essere “in-tra". In: TREVISAN SEMI, E. (Ed.). Mediterraneo e migrazione oggi. Venezia:Il ponte,2006. p. 51-68.

GHAZY, R. Oggi forse non ammazzo nessuno. Milano: Fabbri editore, 2007.

GUOLO, R. Xenofobi e xenofili: Gli italiani e l'Islam. Roma-Bari: Editori Laterza, 2003.

HERVIEU LEGER, D. Religione e memoria. Bologna: Il Mulino, 1993.

HIRSCH, M. The generation of postmemory. Poetics Today, Durham, v. 29, n. 1, p. 103128, 2008.

MUXEL A. Individu et mémoire familiale. Paris: Nathan, 2002.

PACE, E. Sociologia dell'islam. Roma: Carocci, 1999. 
RHAZZALI, K.; EQUIZI, M. I musulmani e i loro luoghi di culto. In: PACE, Enzo (Ed.). Le religioni nell'Italia che cambia: mappe e bussole. Roma: Carocci, 2013. p. 47-65.

RICOEUR, P. Ricordare, dimenticare, perdonare: l'enigma del passato. Bologna: Il Mulino, 2004.

ROY, O. Global Muslim. Milano: Feltrinelli, 2003.

SAINT BLANCAT, C. La transmission de l'islam auprès des nouvelles generations de la diaspora. Social Compass, London, v. 51, n. 2 , p. 235-247, 2004.

SAINT BLANCAT, C. Musulmans italiens et europeens: devenir acteurs et interlocuteurs dans l'espace public. In: TREVISAN SEMI, E. (Ed.). Mediterraneo e migrazione oggi. Venezia: Il ponte, 2006. p. 225-236.

VENTURA, A. Il Corano. Milano: Mondadori, 2010. 